\title{
ANÁLISE DOS COMPOSTOS VOLÁTEIS DA AGUARDENTE DE CANA POR CONCENTRAÇÃO DINÂMICA DO "HEADSPACE" E CROMATOGRAFIA GASOSA-ESPECTROMETRIA DE MASSAS ${ }^{1}$
}

\author{
Ian Carneiro da Cunha NÓBREGA ${ }^{2, *}$
}

\begin{abstract}
RESUMO
Os compostos voláteis da aguardente de cana foram extraídos por meio da concentração dinâmica do "headspace" em armadilhas contendo Tenax-TA e analisados por cromatografia gasosa-espectrometria de massas. Cerca de 100 compostos voláteis, com número de carbonos que variavam de 5 a 18, foram detectados. Destes, 22 foram selecionados, sendo 18 ésteres, com base nas suas quantidades no extrato ou nas suas características sensoriais obtidas na literatura. Os compostos presentes em maiores quantidades foram o 3-metil-1butanol (álcool isoamílico), 1,1-dietoxi-etano (acetaldeído dietil acetal) e os ésteres acetato de 3-metilbutila, hexanoato de etila, octanoato de etila, decanoato de etila e dodecanoato de etila. Dentre os compostos identificados em menor quantidade, destacou-se, devido a sua natureza química, o composto sulfurado 4,5-de-hidro-2-metil-3(2H)-tiofenona. Esta é a primeira vez que este e outros compostos voláteis são reportados em aguardente de cana. Conclui-se que a metodologia empregada neste trabalho permitiu a identificação de compostos voláteis da fração $\mathrm{C}_{5}-\mathrm{C}_{18}$, que potencialmente contribuem para o aroma da aguardente de cana.

Palavras-chave: aguardente de cana; compostos voláteis; aroma; análise do "headspace”; adsorção; cromatografia gasosa-espectrometria de massas.
\end{abstract}

\section{SUMMARY}

THE ANALYSIS OF VOLATILE COMPOUNDS FROM BRAZILIAN SUGAR CANE SPIRIT BY DYNAMIC HEADSPACE CONCENTRATION AND GAS CHROMATOGRAPHY-MASS SPECTROMETRY. The volatile compounds of Brazilian sugar cane spirit, the fermented and distilled juice of sugar cane, were extracted by dynamic headspace concentration on Tenax-TA trap and analyzed by gas chromatographymass spectrometry. Approximately 100 volatile compounds with carbon number ranging from 5 to 18 were detected. Among these, 18 esters and 4 compounds from other chemical classes were selected for this work on the basis of their quantity in the extract or their sensory qualities obtained from literature. The major compounds identified were 3-methyl-1-butanol (isoamyl alcohol), 1,1-diethoxyethane (acetaldehyde diethyl acetal) and the esters 3-methylbutyl acetate, ethyl hexanoate, ethyl octanoate, ethyl decanoate and ethyl dodecanoate. In minor quantities, potentially important aroma compounds, such as the sulfur-containing 4.5-dehydro-2-methyl-3(2 $H)$ thiophenone, were identified. As far as we are concerned, this is the first time many of these compounds are reported in Brazilian sugar cane spirit. It is concluded that the analytical method was effective for the identification of potentially important aroma compounds of the $\mathrm{C}_{5}-\mathrm{C}_{18}$ fraction.

Keywords: brazilian sugar cane spirit; volatile compounds; aroma; headspace analysis; adsorption; gas chromatography-mass spectrometry.

\section{1 - INTRODUÇÃO}

A aguardente de cana brasileira é uma das bebidas alcoólicas fermento-destiladas mais produzidas no mundo, porém seu consumo está basicamente restrito ao território brasileiro. Uma das razões que explicam a preferência brasileira pela aguardente de cana, ou cachaça, talvez seja histórica ou cultural, tendo em vista que o surgimento da bebida coincide com o próprio processo de colonização do Brasil, a partir da introdução da canade-açúcar entre o séculos XVI e XVII [5]. Outra razão para esta preferência pode residir no simples fato da cachaça possuir, em geral, baixo custo, o que explica a constante associação da bebida com a população de menor poder aquisitivo.

Quaisquer que sejam os motivos que expliquem a preferência brasileira pela cachaça, é razoável supor que as caracteristicas sensoriais da bebida, em especial o seu aroma, também exercem um papel importante nesse processo.

Recebido para publicação em 05/10/2001. Aceito para publicação em 14/10/2002 (000751).

2. Departamento de Tecnologia Rural, Centro de Formação de Tecnólogos, Universidade Federal da Paraíba, Bananeiras - PB, CEP 58.220-000. E-mail:ian.nobrega@uol.com.br

* A quem a correspondência deve ser enviada.
O aroma de um alimento pode ser explicado pela ocorrência de compostos químicos cuja principal característica é a volatilidade, a qual permite que tais compostos sejam percebidos pelos receptores nasais, tanto durante a degustação do alimento (detecção retro-nasal), como pelo odor exalado a distância. Estima-se que o processo de percepção pelo olfato (aroma) é mais sensivel do que pelo paladar (sabor), em fatores que variam na ordem de $10^{6}$ a $10^{9}$ [14]. Ao contrário do paladar, milhares de compostos voláteis podem ser detectados e diferenciados, em menor ou maior escala, pelo olfato. Isso depende de diversos fatores, dentre os quais, a estrutura química do composto volátil e a interação deste com a matriz alimentícia [4]. Tais fatores, por sua vez, são responsáveis por características importantes dos compostos, a exemplo o valor do limiar de odor (limiar de detecção ou "threshold"), que pode ser definido como a concentração minima pela qual um composto pode ser detectado pelo sentido do olfato [4].

O componente volátil majoritário das bebidas alcoólicas é o álcool etílico, ao lado do qual está presente centenas de outros compostos voláteis proporcionalmente minoritários, os quais são formados por rotas químicas ou bioquímicas, durante e após a fermentação alcoólica. Nas classes dos compostos voláteis produzidos por estas vias, incluem-se: ésteres, aldeídos, álcoois superio- 
res (propílico, butílico e amílico), cetonas e hidrocarbonetos [20].

O etanol, devido ao seu valor de limiar de odor elevado (100.000 ppb [4]) e a sua característica de aroma pouco marcante, é provavelmente um dos componentes voláteis de menor destaque na definição ou caracterização do aroma nas bebidas alcoólicas. No entanto, uma parcela significativa dos compostos voláteis possui grande impacto na qualidade do aroma das bebidas alcoólicas, na medida que tais compostos pertencem às classes dos ésteres (como também dos aldeídos, álcoois superiores, entre outros), que geralmente possuem valores de limiar de odor relativamente baixos, assumindo caracteristicas de aroma mais marcantes.

Poucos trabalhos foram realizados até o momento com objetivo de identificar, através de cromatografia gasosa (CG) ou cromatografia gasosa associada com espectrometria de massas (CG-EM), compostos voláteis de importância, ou com potencial de impacto, no aroma da cachaça. Entre os trabalhos pioneiros incluem-se o de ALMEIDA \& BARRETO [1] e o de LLISTÓ et al [13] e, entre os mais recentes, incluem-se o de NASCIMENTO et al [15] e o de NONATO et al. [18].

Desta forma, o objetivo deste trabalho foi contribuir para a identificação dos compostos voláteis relevantes ao aroma da cachaça. Para isso, lançou-se mão de um método de extração de voláteis nunca antes testado para cachaça, a saber: a concentração dinâmica dos compostos voláteis presentes no "headspace" da cachaça em armadilha, contendo o adsorvente Tenax-TA. A identificação e quantificação dos compostos voláteis foram realizadas por meio de cromatografia gasosa - espectrometria de massas (CG-EM).

\section{2 - MATERIAL E MÉTODOS}

\section{1 - Aguardente de cana}

Foram adquiridas três garrafas de uma mesma marca de aguardente de cana no comércio da cidade de João Pessoa, PB. Os aguardentes, comercializados em todo o país e elaborados por uma empresa engarrafadora de grande porte, possuíam aspecto incolor e graduação alcoólica de $40^{\circ} \mathrm{GL}$.

Todas as análises descritas a seguir foram realizadas no Laboratório de Química de Aroma da Universidade de Reading, Inglaterra.

\section{2 - Extração de compostos voláteis do "headspace" da aguardente de cana e adsorção em Tenax-TA.}

Uma aliquota de $40 \mathrm{~mL}$ de cada garrafa foi diluída em $40 \mathrm{~mL}$ de água destilada e a mistura transferida para um erlenmeyer de $250 \mathrm{~mL}$ com boca rosqueada. No erlenmeyer, foi rosqueada uma tampa vazada contendo uma arruela seladora interna, ambos feitos de politetrafluoroeteno-PTFE (SVL fittings; J. Bibby Science Products). Um aparato de vidro foi acoplado através da tampa e, na sua extremidade de fora, adaptou-se uma peça feita em aço inoxidável. Uma armadilha, composta de tubo de aço inoxidável (155mm de comprimento $\mathrm{x}$ $3 \mathrm{~mm}$ de diâmetro interno) e revestida internamente com 85mg do adsorvente Tenax-TA (SGE Ltd, Australia), foi conectada à citada peça. Os voláteis presentes no "headspace" da amostra foram arrastados em direção ao Tenax-TA, por meio de um fluxo de nitrogênio $(40 \mathrm{~mL} /$ min) livre de oxigênio (Figura 1).

O tempo de extração foi de 60 minutos, durante o qual a amostra foi mantida em banho-maria a $37^{\circ} \mathrm{C}(\mathrm{Fi}-$ gura 1). Para garantir a ausência de compostos orgânicos no fluxo de nitrogênio, este último foi previamente eluído através de carvão ativo granular (Figura 1). O fluxo foi ajustado em $60 \mathrm{~mL} / \mathrm{min}$ por meio de regulador de pressão e de um controlador de fluxo de massa. Após 60 minutos, o frasco foi removido e a armadilha conectada a um fluxo de nitrogênio puro $(40 \mathrm{~mL} / \mathrm{min})$ para remoção de traços de umidade. Um microlitro do padrão interno 1,2-diclorobenzeno (200ng em $1 \mu \mathrm{L}$ de dietil éter) foi adicionado à armadilha, antes da análise por CGEM. Três repetições analiticas foram realizadas.

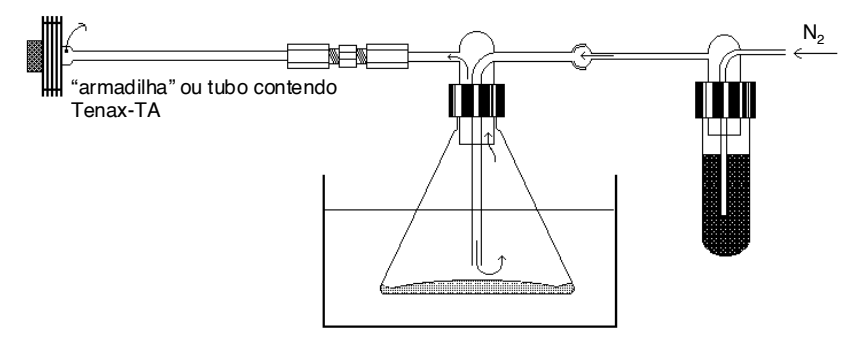

FIGURA 1. Aparato utilizado na concentração dinâmica do "headspace" da cachaça em Tenax-TA.

\section{3 - Cromatografia gasosa - espectrometria de massas}

A análise dos compostos adsorvidos na armadilha de Tenax-TA foi realizada por meio de um cromatógrafo a gás Hewlet-Packard HP5890, acoplado a um detector seletivo de massa HP5972. Os compostos foram separa-

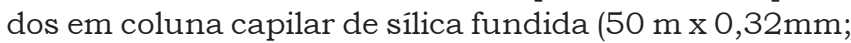
espessura do filme 0,5 $\mu \mathrm{m}$; SGE Ltd.) com fase BPX5 (5\% fenil polisilfenileno-siloxano) e hélio como gás de arraste $(1,6 \mathrm{~mL} / \mathrm{min})$. A interface do CG com o detector seletivo de massas foi mantida a $280^{\circ} \mathrm{C}$. O detector seletivo de massa foi operado em modo de impacto eletrônico, energia de ionização de $70 \mathrm{eV}$ e taxa de rastreamento de 1,9 por segundo sobre uma amplitude de 29 a 400 unidades de massa atômica. Os dados gerados foram controlados e armazenados pelo HP 5970 Chemstation Data System. Um sistema de injeção do tipo "concentrator/headspace" (CHIS, SGE Ltd.) foi utilizado para introduzir as armadilhas no CG. Essas armadilhas foram submetidas a um aquecimento a $250^{\circ} \mathrm{C}$ no CHIS, o que resultava na liberação dos voláteis do Tenax-TA para o CG. Simultaneamente, os voláteis liberados foram concentrados por meio de nitrogênio liquido, na cabeça da coluna, enquanto que o forno do $\mathrm{CG}$ foi mantido a $\mathrm{O}^{\circ} \mathrm{C}$, durante 5 minutos. A temperatura do forno foi então elevada até $40^{\circ} \mathrm{C}$ por 2 minutos e, em seguida, programada até $280^{\circ} \mathrm{C}$, a uma taxa de $4^{\circ} \mathrm{C} / \mathrm{min}$. 


\section{4 - Identificação e quantificação dos compostos voláteis}

Uma solução contendo uma série homóloga de n-alcanos $\left(\mathrm{C}_{6}-\mathrm{C}_{22}\right)$ foi analisada por CG-EM, de forma a permitir a conversão dos tempos de retenção de cada composto volátil em indices de retenção linear (IRL). Os voláteis foram identificados por meio da comparação de seus espectros de massas e IRL com aqueles obtidos de bancos de dados de referência ou de outros trabalhos publicados. A quantificação dos compostos no "headspace" da aguardente de cana foi estimada por meio da comparação das áreas dos picos dos compostos e da área de 200ng do 1,2-diclorobenzeno (padrão interno). (Sobre os valores (três repetições) quantificados dos compostos voláteis, foram calculadas médias aritméticas e coeficientes de variação (CV)).

\subsection{1 - Determinação dos indices de retenção li- near (IRL)}

Uma mistura de $n$-alcanos $(1 \mu \mathrm{L})$ foi injetada na armadilha, a qual foi introduzida no CG-EM, seguindo-se a mesma metodologia descrita anteriormente. Os indices de retenção linear (IRL) dos compostos voláteis foram calculados a partir dos tempos de retenção destes e dos n-alcanos, utilizando-se a seguinte equação:

$$
I R L_{x}=\left[\frac{T R_{x}-T R_{n}}{T R_{n+1}-T R_{n}}+n\right] \times 100
$$

onde:

$\mathrm{IRL}_{\mathrm{x}}=$ indice de retenção linear de um composto $\mathrm{x}$ $\mathrm{TR}_{\mathrm{x}}{ }_{\mathrm{x}}=$ tempo de retenção do composto $\mathrm{x}$

$\mathrm{TR}_{\mathrm{n}}=$ tempo de retenção do n-alcano antes do composto $\mathrm{x}$ $\mathrm{TR}_{\mathrm{n}+1}=$ tempo de retenção do $\mathrm{n}$-alcano depois do composto $\mathrm{x}$ $\mathrm{n}=$ número de carbonos do n-alcano antes do composto $\mathrm{x}$

\section{3 - RESULTADOS E DISCUSSÃO}

As quantidades dos 22 compostos voláteis identificados no "headspace" da cachaça são mostradas na Tabela 1. Além de dados quantitativos, também são apresentados indices de retenção linear (IRL) em ordem crescente, métodos de identificação e dados de espectrometria de massas (EM), acompanhados dos números de identificação (NI) dos compostos, os quais são algumas vezes utilizados ao invés do nome do composto, no transcorrer desta discussão (Tabela 1). As estruturas químicas dos 22 compostos são mostradas na Figura 2 e o cromatograma iônico total (CIT) da cachaça é mostrado na Figura 3.

A maioria dos compostos voláteis presentes no "headspace" da cachaça foram ésteres, sendo 18 deles identificados no presente trabalho (Tabela 1; Figura 2). Compostos identificados de outras classes incluíram os acetais 1,1,-dietoxi-etano e 1-etoxi-1-pentoxi-etano, o álcool superior 3-metil-1-butanol (álcool isoamílico) e o composto sulfurado 4,5-de-hidro-2-metil-3(2H)-tiofenona (Tabela 1; Figura 2).

TABELA 1. Índice de retenção linear (IRL), espectrometria de massas, identificação, quantidade aproximada (ng) e coeficiente de variação (CV) de alguns compostos voláteis presentes no "headspace" da aguardente de cana.

\begin{tabular}{|c|c|c|c|c|c|c|}
\hline $\mathrm{NI}^{\mathrm{a}}$ & Composto & $\mathrm{IRL}^{\mathrm{b}}$ & ${\text { Espectrometria de Massas }(E M)^{\circ}}^{c}$ & Identificação $^{d}$ & $\begin{array}{l}\text { Quant. } \\
(\mathrm{ng})^{\mathrm{e}}\end{array}$ & $\begin{array}{l}\mathrm{CV} \\
(\%)^{f}\end{array}$ \\
\hline & Ésteres & & & & & \\
\hline 01 & Propanoato de etila & 725 & 29(100), 57(96), 45(16), 75(13), 74(13), 43(12), 42(11), 102(10). & $\mathrm{EM}^{[16]}+\mathrm{IRL}^{[2]}$ & 64 & 18 \\
\hline 04 & Butanoato de etila & 816 & $71(100), 43(83), 88(60), 60(25), 29(25), 73(24), 89(16), 45(15), 61(10), 101(10)$. & $\mathrm{EM}^{[16]}+\mathrm{IRL}^{[2 ; 11]}$ & + & - \\
\hline 05 & Acetato de 3-metilbutila & 898 & 43(100), 70(50), 55(42), 41(21), 42(19), 39(12), 29(11), 87(10). & $\mathrm{EM}^{[16]}+\mathrm{IRL}^{[2 ; 11]}$ & 4876 & 35 \\
\hline 06 & Pentanoato de etila & 917 & 29(100), 85(76), 41(70), 88(68), 57(60), 43(56), 9(45), 101(43), 60(38), 55(35). & $\mathrm{EM}^{[16]}+\mathrm{IRL}^{[2]}$ & 201 & 14 \\
\hline 08 & Hexanoato de etila & 1017 & $88(100), 43(68), 29(62), 99(48), 60(44), 41(35), 73(32), 70(30), 42(28), 101(26), 61(25), 71(24)$. & $\mathrm{EM}^{[16]}+\mathrm{IRL}^{[2]}$ & 3056 & 24 \\
\hline 10 & Acetato de hexila & 1027 & 43(100), $41(32), 56(25), 55(23), 42(20), 29(18), 39(18), 61(16), 69(12), 73(6)$ & $\mathrm{EM}^{[16]}+\mathrm{IRL}^{[11 ; 10]}$ & 57 & 32 \\
\hline 11 & Heptanoato de etila & 1110 & 88(100), 29(77), $41(75), 43(55), 55(33), 113(48), 101(40), 60(37), 39(37), 73(35), 115(24), 70(23)$. & $\mathrm{EM}^{[16]}+\mathrm{IRL} L^{[11]}$ & 311 & 20 \\
\hline 12 & Octanoato de etila & 1213 & $88(100), 29(45), 41(36), 101(32), 57(30), 43(27), 60(27), 55(26), 73(26), 127(22), 70(22), 61(20)$ & $\mathrm{EM}^{[16]}+\mathrm{IRL}^{[2 ; 10]}$ & 6331 & 15 \\
\hline 13 & Nonanoato de etila & 1308 & 88(100), 41(60), 101(52), 29(52), 55(46), 43(34), 141(32), 73(31), $60(23), 39(22), 70(21), 42(21)$. & $\mathrm{EM}^{[16]}$ & 150 & 19 \\
\hline 14 & Decanoato de etila & 1424 & $88(100), 101(38), 29(33), 41(31), 43(27), 73(23), 55(22), 70(20), 60(18), 61(16), 155(14), 157(14)$. & $\mathrm{EM}^{[16]}+\mathrm{IRL}^{[11]}$ & 7476 & 10 \\
\hline 15 & Octanoato de 3-metilbutila & 1467 & 70(100), 41(67), 43(65), 55(56), 127(41), 57(36), 71(31), 29(30), 42(22), 145(17), 69(11). & $\mathrm{EM}^{[16]}$ & 178 & 22 \\
\hline 16 & Undecanoato de etila & 1509 & $88(100), 101(53), 41(50), 29(40), 55(38), 43(32), 73(27), 169(21), 157(17)$ & $\mathrm{EM}^{[16]}$ & 88 & 20 \\
\hline 17 & Dodecanoato de etila & 1618 & 88(100), 101(46), 41(32), 43(29), 29(29), 55(26), 73(21), 70(18), 57(14), 60(14), 61(14), 157(11). & $\mathrm{EM}^{[16]}+\mathrm{IRL}^{[2]}$ & 3449 & 26 \\
\hline 18 & Decanoato de 3-metilbutila & 1664 & 70(100), 43(68), 41(54), 55(53), 71(40), 29(21), 69(15), 39(14), 155(13), 173(12). & $\mathrm{EM}^{[16]}$ & 506 & 44 \\
\hline 20 & Dodecanoato de 3-metilbutila & 1849 & 70(100), 43(52), 71(39), 41(36), 55(34), 183(18), 57(14), 29(12), 201(11), 42(10), 39(18), 83(7). & $\mathrm{EM}^{[16]}$ & 46 & 38 \\
\hline 21 & Pentadecanoato de etila & 1897 & 88(100), 101(52), 41(41), 43(36), 55(33), 57(23), 29(21), 73(19), 157(18), 69(17), 89(15), 70(14). & $\mathrm{EM}^{[16]}$ & 11 & 40 \\
\hline \multirow[t]{2}{*}{22} & Hexadecanoato de etila & 1997 & 88(100), 101(66), 41(36), 43(32), 55(31), 29(23), 157(20), 73(18), 57(17), 89(16), 70(16), 69(15). & $\mathrm{EM}^{[16]}+\mathrm{IRL}^{[2]}$ & 40 & 40 \\
\hline & Outros & & & & & \\
\hline 02 & 1,1-dietoxi-etano & 740 & 45(100), 73(77), 29(33), 47(29), 103(26), 43(24), 75(8), 31(6). & $\mathrm{EM}^{[16]}$ & 4554 & 34 \\
\hline 03 & 3-Metil-1-butanol & 776 & 41(100), 55(98), 42(75), 70(64), 29(62), 43(60), 31(59), 57(48). & $\mathrm{EM}^{[16]}+\mathrm{IRL} \mathrm{L}^{[2 ; 11]}$ & +++ & - \\
\hline 07 & 1-etoxi-1-pentoxi-etano & 977 & 73(100), 45(70), 43(58), 71(50), 29(25), 41(24), 145(20), 55(15), 39(13), 115(12). & $\mathrm{EM}^{[16]}$ & 1112 & 13 \\
\hline 09 & 4,5-De-hidro-2-metil-3(2H)-tiofenona & 1024 & $60(100), 116(35), 59(33), 45(27), 41(23), 39(17), 58(15), 29(14)$ & $\mathrm{EM}^{[16]}+\mathrm{IRL}^{[17]}$ & 158 & 13 \\
\hline
\end{tabular}
aNúmero do composto para fins de identificação neste trabalho. bíndice de retenção linear (IRL) calculado com relação a n-alcanos $\left(\mathrm{C}_{5}-\mathrm{C}_{22}\right)$ e coluna capilar com fase BPX5. ${ }^{\circ}$ Ions mais abundantes são citados em ordem decrescente de intensidade relativa (percentual entre parênteses). ¿Identificação do composto realizada por comparação dos dados de EM e IRL gerados neste trabalho com dados da literatura, a saber: ACREE \& HEINRICH [2], GÓMEZ et al [10], KONDJOYAN \& BERDAGUÉ [11], NIST/EPA/MSDC [16] e
NOBREGA [17]. 'Quantidade Média (três repetições) do composto, em nanogramas (ng), calculada por meio de padrão interno (1,2-diclorobenzeno); +, presente em quantidades

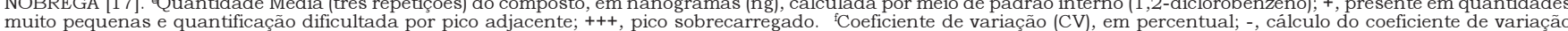
muito pequenas e quantificação dificultada por pico adjacente; +++ , pico
inviabilizado devido as quantidades médias não terem sido calculadas 


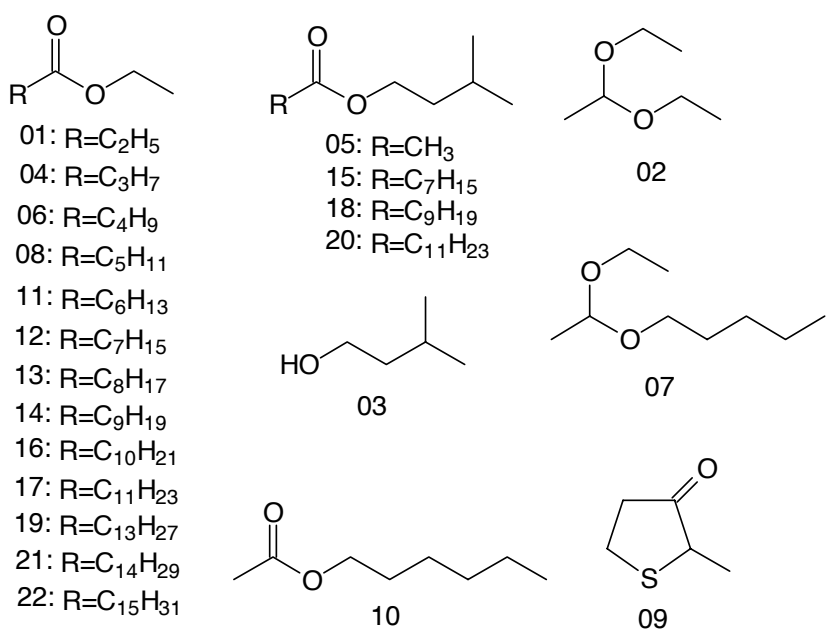

FIGURA 2. Compostos voláteis identificados no "headspace" da cachaça. Os números dos compostos acima correspondem aos números de identificação (NI) dos compostos listados na Tabela 1 .

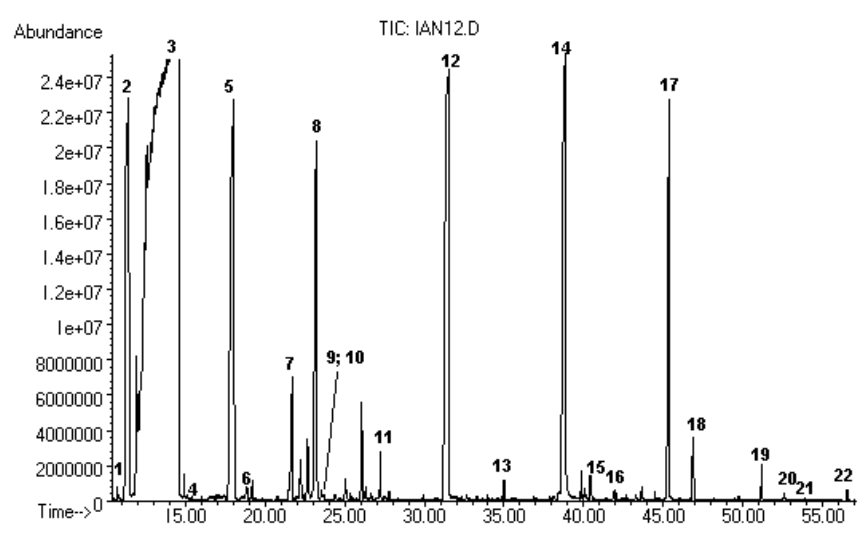

FIGURA 3. Cromatograma iônico total (TIC) da cachaça. Os números dos picos correspondem aos números de identificação (NI) dos compostos listados na Tabela 1.

\section{1 - Método}

A concentração dinâmica do "headspace" da cachaça em uma armadilha de Tenax [poli(óxido de 2,6-defenil$p$-fenileno)], associada com a desorção térmica da armadilha em um CG-EM equipado com coluna BPX-5, permitiu a detecção de cerca de 100 compostos voláteis (Figura 3). No entanto, com base nos compostos com potencial de aroma identificados neste trabalho, 22 deles foram selecionados (Tabela 1) tendo como critério as quantidades no extrato e as características de aroma e os valores de limiar de odor obtidos na literatura. A resolução cromatográfica obtida foi boa, porém o 3-metil1-butanol (álcool isoamílico) apresentou-se de forma sobrecarregada no cromatograma (Figura 3).

Similarmente ao presente trabalho, NONATO et al [18], extraindo o aroma do "headspace" da cachaça por meio de microextração em fase sólida (SPME) com fibra de poliacrilato e analisando-os via CG-EM, foram capazes de detectar um grande número de compostos. Des- tes, 38 foram identificados, sendo que 11 eram ésteres. No entanto, dados de EM e IRL dos compostos não foram apresentados.

Em comparação ao presente trabalho, é interessante observar que o método empregado por NONATO et al [18] foi capaz de extrair uma amplitude maior de compostos, em especial aqueles da fração carbônica "leve" $\left(\mathrm{C}_{2}-\mathrm{C}_{5}\right)$, incluindo ácido acético $\left(\mathrm{C}_{2}\right)$ e acetato de etila $\left(\mathrm{C}_{3}\right)$. Compostos voláteis da fração "média" $\left(\mathrm{C}_{6}-\mathrm{C}_{14}\right)$ e "pesada" $\left(\mathrm{C}_{15}-\mathrm{C}_{22}\right)$ também foram extraídos. Já o método empregado no presente trabalho mostrou sensibilidade apenas para a fração "média" e "pesada". Essa perspectiva mais limitada pode justificar-se pelo fato de a fração "leve" possuir um tempo de retenção na armadilha de TenaxTA menor do que o tempo de extração empregado $(60$ minutos), o que pode ter resultado na perda desses compostos pela armadilha. Além do mais, a armadilha de Tenax-TA não é particularmente recomendada para reter compostos voláteis com pontos de ebulição muito baixos ou que sejam muito leves, sendo mais indicada para adsorver compostos com número de carbonos maior do que seis, ou entre um e cinco, dependendo do grupo funcional [6].

A limitação do método de extração empregado no presente trabalho não chega a comprometer os resultados, tendo em vista que no caso de ésteres, por exemplo, a fração dos compostos compreendidos entre o hexanoato de etila $\left(\mathrm{C}_{8}\right)$ e o dodecanoato de etila $\left(\mathrm{C}_{14}\right)$ é considerada a mais importante, devido aos odores dos ésteres desta fração serem responsáveis pelo odor característico das bebidas alcoólicas fermento-destiladas em geral [20].

\section{2 - Ésteres}

Ao lado dos álcoois superiores (propílico, butílico e amílico), os ésteres são, quantitativamente e qualitativamente, um dos maiores grupos de compostos da fração volátil das bebidas alcoólicas [12].

A principal origem dos ésteres, nas bebidas alcoólicas, está no metabolismo secundário intracelular das leveduras durante a fermentação alcoólica. Estes ésteres são formados por reações enzimáticas entre ácidos ativados sob a forma de acetil-SCoA e álcoois correspondentes. A formação de ésteres pós-fermentação alcoólica, via reação química direta entre álcoois e ácidos, também ocorre, porém em escala bem menor que a via enzimática. Dentre os ésteres existentes, os tipos etilicos de ácidos graxos e acetatos são considerados importantes em bebidas alcoólicas, devido às suas concentrações serem relativamente elevadas, às suas características de aroma serem agradáveis e aos seus valores de limiar de odor serem relativamente baixos [3, 7].

Os ésteres mais abundantes nas bebidas tendem a ser aqueles derivados dos ácidos e dos álcoois mais abundantes. Em trabalho de avaliação qualitativa e quantitativa de ácidos voláteis, em 57 marcas de cachaça provenientes de diferentes regiões do Brasil, NASCIMENTO et al. [15] constataram que os ácidos voláteis presentes em maiores quantidades nas cachaças eram: o acético (9095\% do total dos 14 ácidos identificados), o octanóico, o 
decanóico e o dodecanóico. Já com relação à ocorrência de álcoois superiores em cachaças de diversas procedências, tanto ALMEIDA \& BARRETO [1] como NONATO et al [18], identificaram os álcoois isoamílico (3-metil-1butanol), isobutílico e propílico como majoritários.

Os resultados qualitativos e quantitativos dos ésteres identificados nesta pesquisa estão alinhados com os resultados encontrados por NASCIMENTO et al [15], ALMEIDA \& BARRETO [1] e NONATO et al [18] em pesquisas sobre a ocorrência de álcoois superiores e ácidos em aguardentes. Dos 18 ésteres identificados no presente trabalho, os 5 majoritários que relacionam-se aos ácidos e álcoois majoritários identificados nas pesquisas supracitadas são: decanoato de etila (derivado do ácido decanóico e etanol), octanoato de etila (derivado do ácido octanóico e etanol), acetato de 3-metilbutila (derivado do ácido acético e 3-metil-1-butanol) e dodecanoato de etila (derivado do ácido dodecanóico e etanol) (Tabela 1). É interessante observar que a grande quantidade de 3-metil-1-butanol está coerente com os altos teores do seu derivado éster, o acetato de 3-metilbutila, ambos encontrados na cachaça analisada (Tabela 1; Figura 3).

O resultado obtido para hexanoato de etila (Tabela 1), derivado do ácido hexanóico e etanol, no entanto, não está alinhado com a investigação sobre ácidos realizada por NASCIMENTO et al [15]. Esses autores não encontraram quantidades de ácido hexanóico suficientemente altas nos diversos tipos de cachaças que possam justificar a alta concentração de hexanoato de etila encontrada neste estudo.

Comparando-se os ésteres encontrados nesta pesquisa com os identificados por NONATO et al [18], conclui-se que os ésteres aqui apresentados são mais abrangentes, dentre os quais ésteres com alto potencial de contribuição ao aroma da cachaça. Dos 18 ésteres aqui identificados, 12 não foram reportados por NONATO et al [18], a saber: 01, 04, 06, 10, 11, 13, 16, 19 e 20 (Tabela 1), além do $05,15,18$ e 20, que são derivados do $3-$ metil-1-butanol (Tabela 1). No entanto, dentre os 13 ésteres identificados por NONATO et al. [18], 7 não foram identificados no presente trabalho, com destaque para o acetato de etila.

Os odores específicos dos ésteres majoritários, identificados nesta pesquisa, decanoato de etila, hexanoato de etila, octanoato de etila e acetato de 3-metilbutila ( $\mathrm{Ta}$ bela 1), foram reportados por ACREE \& HEINRICH [2] como "uva", "casca de maçã", "frutado" e "banana", respectivamente. Destes, no entanto, só o valor de limiar de odor em água para acetato de 3-metilbutila, que é de 19 ppb [21], foi encontrado na literatura. Além da cachaça, os ésteres referidos têm sido também reportados em vinho, cerveja, conhaque francês e uisque escocês $[3,7$, 20]. Outro éster majoritário encontrado na cachaça, dodecanoato de etila, tem odor descrito por ACREE \& HEINRICH [2] como "folha de planta". No entanto, ésteres com estruturas carbônicas mais "pesadas", como é o caso do dodecanoato de etila, têm, em geral, menor volatilidade e maior valor de limiar de odor, sendo sua contribuição sensorial supostamente limitada mais à textura (oleosidade) e ao palato do que ao aroma.

Os ésteres minoritários encontrados na cachaça estudada são potencialmente importantes ao aroma, pois apresentam valores de limiar de odor baixos em água, tais como: propanoato de etila (5ppb) [22], butanoato de etila (1 ppb) [21], pentanoato de etila (5ppb) [24], acetato de hexila (2ppb) [21] e heptanoato de etila (2ppb) [23].

Os odores do propanoato de etila, butanoato de etila, pentanoato de etila e acetato de hexila têm sido descritos individualmente na literatura como "frutado" [2], "maçã" [2], "fermento" [2] e "frutado" [21], respectivamente.

Os valores de limiar de odor dos ésteres minoritários são bem mais baixos do que de alguns ésteres majoritários da aguardente de cana, em especial, do acetato de etila, cujo valor em água tem sido reportado como 1.000 ppb [23].

\section{3 - Outros compostos}

Além dos ésteres, compostos de outras classes químicas apresentaram-se de forma marcante no "headspace" da cachaça estudada. Um desses foi o álcool superior 3-metil-1-butanol (Tabela 1; Figura 2), também conhecido como álcool isoamílico. Apesar de não ter sido possivel sua quantificação (Seção 3.1; Figura 3), o 3-metil-1-butanol (álcool isoamílico) foi o composto dominante no "headspace" da cachaça.

Devido aos álcoois superiores, em particular o 3metil-1-butanol, serem relativamente comuns e abundantes em bebidas alcoólicas, muitas informações sobre os mesmos estão disponiveis na literatura. A principal rota de formação dos álcoois superiores é o catabolismo secundário nas leveduras de açúcares e aminoácidos, preferencialmente destes últimos, durante a fermentação alcoólica [7, 20].

Assim como constatado neste estudo, ALMEIDA et al. [1] e NONATO et al. [18], utilizando técnicas distintas de análise, também reportaram concentrações relativamente elevadas de 3-metil-1-butanol em cachaças de diversas procedências. O 3-metil-1-butanol também é o álcool superior dominante em bebidas alcoólicas como vinhos [7], cervejas [3], rum, uísque e conhaque [20].

O valor de limiar de odor do 3-metil-1-butanol em água, $1.000 \mathrm{ppb}$ [21], é relativamente elevado. Apesar disto, a contribuição do 3-metil-1-butanol ao aroma final tende a ser elevada, tendo em vista sua alta concentração no "headspace" da bebida. Em termos de características de odor, 3-metil-1-butanol tem sido caracterizado como "uísque" [2] e "malte" [21], além de "alcoólico", "vinico", "banana" e "doce" [3]. No entanto, é importante levar em consideração que as características de odor dos compostos voláteis dependem de suas concentrações, de forma que quantidades muito elevadas podem modificar características de odor consideradas "agradáveis" para "extremamente desagradáveis", condição essa igualmente observada em alguns compostos voláteis sulfurados [8]. 
Uma outra classe de compostos presente em quantidades relativamente elevadas no "headspace" da cachaça é a dos acetais, incluindo o 1,1-dietoxi-etano (acetaldeído dietil acetal) e o 1-etoxi-1-pentoxi-etano (acetaldeído etil pentil acetal) (Tabela 1; Figura 2; Figura 3). Estes compostos são formados através da reação entre aldeídos e álcoois, fazendo com que o odor "pungente" dos aldeídos nas bebidas alcoólicas seja reduzido à medida que essas reações ocorrem [7, 20].

Como o aldeído e o álcool majoritários nas bebidas alcoólicas é o acetaldeído e o etanol, não é surpreendente constatar que niveis relativamente elevados de 1,1 ,dietoxi-etano foram encontrados no "headspace" da cachaça estudada (Tabela 1). A formação de 1,1-dietoxietano pode ser demonstrada pela reação de adição entre acetaldeído e etanol, formando um hemiacetal, seguido pela condensação deste com outra molécula de etanol, o que resulta na formação de 1,1-dietoxi-etano (Figura 4).

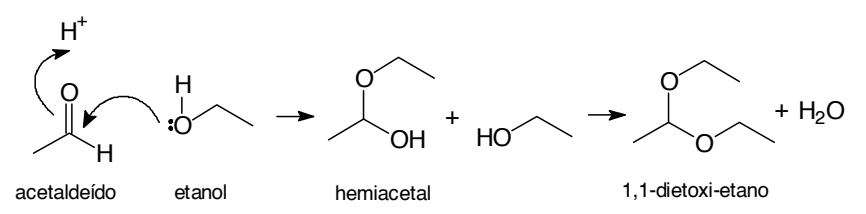

FIGURA 4. Formação de 1,1-dietoxi-etano a partir de acetaldeído e etanol.

O 1,1-dietoxi-etano tem valor de limiar de odor em água de $40 \mathrm{ppb}$ [24] e características de odor reportadas como "refrescante", "frutado" e "verde" [26]. Assim, o 1,1dietoxi-etano deve contribuir para o aroma final da cachaça, seja pela redução do odor "pungente" do aldeído majoritário na cachaça (acetaldeído), seja pelo provimento das características de aroma citadas.

Com relação ao outro acetal identificado na cachaça, o 1-etoxi-1-pentoxi-etano, não foi encontrado o valor de limiar de odor ou a característica de odor deste composto na literatura. Apesar de ter havido bastante similaridade dos dados de EM gerados neste estudo, com aqueles reportados para o 1-etoxi-1-pentoxi-etano pelo NIST/EPA/MSDC [16], a confirmação pelo índice de retenção linear (IRL) não foi realizada, devido ao mesmo não ter sido encontrado na literatura. Estas observações levantam a possibilidade de tal composto não ser o 1-etoxi-1-pentoxi-etano, mas o 1-etoxi-1-(3metilbutoxi)etano. Novamente, dados de EM ou IRL do 1-etoxi-1-(3-metilbutoxi)etano não foram encontrados na literatura para comparação. A razão do composto em questão poder ser o 1-etoxi-1-(3-metilbutoxi)etano, cujo peso molecular é igual ao do 1-etoxi-1-pentoxi-etano, explica-se pelo fato do mesmo ser resultado da participação de um composto bastante abundante na cachaça além do acetaldeído e do etanol: o 3-metil-1-butanol ( $T a-$ bela 1).

Ainda que em quantidades muito baixas, um composto volátil contendo enxofre também foi encontrado na cachaça, o 4,5-de-hidro-2-metil-3(2H)-tiofenona ( $\mathrm{Ta}$ bela 1; Figura 2). Como pode ser observado na Tabela 1 , a identidade deste composto sulfurado foi confirmada por dados de EM e IRL obtidos na literatura. Esta é a primeira vez que 4,5-de-hidro-2-metil-3(2H)-tiofenona é reportado como composto volátil da cachaça, porém já houve relato da ocorrência do mesmo em rum [19], que também é uma bebida fermento-destilada derivada da cana-de-açúcar. Não foi encontrado o valor de limiar de odor do 4,5-de-hidro-2-metil-3(2H)-tiofenona, porém sua característica de odor é descrita como "verde" e "café queimado" [9].

O 4,5-de-hidro-2-metil-3(2H)-tiofenona é supostamente formado através da fermentação do aminoácido sulfurado metionina [9]. Alternativamente, uma condensação aldol envolvendo acetaldeído e piruvaldeído e subseqüente reação com $\mathrm{H}_{2} \mathrm{~S}$, produzido por intermédio da hidrólise térmica ou degradação de Strecker do aminoácido sulfurado cisteína, também pode levar a formação de 4,5-de-hidro-2-metil-3(2H)-tiofenona [25].

Compostos voláteis sulfurados são considerados relevantes ao aroma de qualquer alimento ou bebida, pois a maioria deles possui valor de limiar de odor muito baixo, tais como: o etiltiol, o dimetilsulfeto e o bis(2-metil3-furil) disulfeto, cujos valores (ppb, em água) são $8 \mathrm{x}$ $10^{-3}, 1$ e $2 \times 10^{-5}$, respectivamente [4].

\section{4 - CONCLUSÕES}

O método analítico empregado permitiu a identificação de importantes compostos voláteis na aguardente de cana, particularmente ésteres. No entanto, o método se mostrou pouco eficiente para reter compostos voláteis de baixo peso molecular, particularmente aqueles com número de carbonos menor do que 5 .

Dentre os 18 ésteres identificados, acredita-se que o acetato de 3-metilbutila, o hexanoato de etila, o octanoato de etila, o decanoato de etila e o dodecanoato de etila, tendo em vista suas quantidades majoritárias no "headspace", são compostos potencialmente importantes ao aroma da aguardente de cana. Ésteres identificados em quantidades minoritárias, tais como: propanoato de etila, butanoato de etila, pentanoato de etila, acetato de hexila e heptanoato de etila, também são potencialmente importantes, tendo em vista seus baixos valores de limiar de odor reportados pela literatura. Os ésteres identificados nesta pesquisa são provavelmente responsáveis pelos caracteres gerais "frutados" do aroma final da aguardente de cana.

Além dos ésteres, o 3-metil-1-butanol (álcool isoamílico) e o 1,1-dietoxi-etano, tendo em vista seus altos teores, e o 4,5-de-hidro-2-metil-3(2H)-tiofenona, devido a presença de enxofre em sua estrutura, também são compostos voláteis identificados no "headspace" da cachaça, que são potencialmente importantes ao aroma final da bebida.

\section{5 - REFERÊNCIAS}

[1] ALMEIDA, M. E. W. de; BARRETO, H. H. C. Álcoois superiores em aguardente de cana por cromatrografia em fase gasosa. R. Inst. Adolfo Lutz, v.31, p.117-124, 1971. 
[2] ACREE, T. ; HEINRICH, A. Gas chromatography olfactometry (GCO) of natural products. Kovacts Retention indices sorted by DB5. Cornell University, 1997. (disponivel em http://nysaes.cornell.edu/ flavornet)

[3] ANGElino, S. A. G. F. Beer. In: MAARse, H. (Ed) Volatile compounds in foods and beverages. New York; Marcel Dekker, 1991. Cap.16, p.581-615.

[4] BELITZ, H-D; GROSCH, W. Aroma Substances. In: BELITZ, H-D.; GROSCH, W. (Eds) Food Chemistry. Berlin; Springer-Verlag, 1999. Cap.5, p.319-377.

[5] CÂMARA CASCUDO, L. 1968. Prelúdio da cachaça. Instituto do Açúcar e do Álcool, Rio de Janeiro.

[6] CONCENTRATOR/HEADSPACE analysis injector. Australia: SGE 1993. (Publication No. MN-0133-A, 6/93).

[7] ETIÉVANT, P. X. Wine. In: MAARse, H. (Ed) Volatile compounds in foods and beverages. New York; Marcel Dekker, 1991. Cap.14, p.483-546.

[8] FARMER L. J.; MOTTRAM, D. S.; WHITFIELD, F. B. Volatiles compounds produced in Maillard reactions involving cysteine, ribose and phospholipid. J. Sci. Food Agric., v.49, p.347-368, 1989.

[9] FLAMENT, I. Coffee, cocoa and tea. In: MAARSE, H. (Ed) Volatile compounds in foods and beverages. New York: Marcel Dekker, 1991. Cap.17, p.617-669.

[10] GÓMEZ, E.; LEDBETTER, C. A.; HARTSELL, P. L. Volatile compounds in apricot, plum, and their interspecific hybrids. J. Agric. Food Chem., v.41, n. 10, p. 1669-1676, 1993.

[11] KONDJOYAN, N.; BERDAGUÉ, J. -L. 1996. A compilation of Relative Retention Indices for the analysis of aromatic compounds. INRA de THEIX, Saint Genes Champanelle, France.

[12] LEHTONEN, M.; JOUNELA-ERICKSSON, P. Volatile and non-volatile compounds in the flavour of alcoholic beverages. In: PIGGOTT, J. R. (Ed) Flavour of distilled beverages: origin and development. Chichester: Ellis Horwood Limited, 1983. Cap.4, p.64-78.

[13] LLISTÓ, A. M. S. M.; SOUZA, L. G.; MISCHAN, M. M. Alguns componentes do coeficiente não-álcool das aguardentes de cana: ésteres. Brasil Açucareiro, v.5, p.341346, 1979.

[14] MOTTRAM, D. S. Aroma. In: MACRAE, R.; ROBINSON, R.; SADLER, M. (Eds) Encyclopaedia of Food Science, Food Technology and Nutrition. London: Academic Press, 1993, p.4065-4071.
[15] NASCIMENTO, R. F.; CARDOSO, D. R.; LIMA NETO, D. S.; FRANCO, D. W. Determination of acids in brazilian sugar cane spirits and other alcoholic beverages by HRGCSPE. Chromatographia, v.48, n.866, p.757-737, 1998.

[16] NIST/EPA/MSDC. 1992. Mass spectral database (version for PC and for mass spectrometer data systems). Office of standard reference data of the national institute of standards and technology, Gaithersburg, Maryland.

[17] NOBREGA, I. C. C. Some aspects of the formation and release of volatile sulphur compounds in meat systems. Reading, 1999. 142p. Ph.D. Thesis, The University of Reading.

[18] NONATO, E. A.; CARAZZA, F.; SILVA, F. C.; CARVALHO, C. R.; CARDEAL, Z. de L. A headspace solid-phase microextraction method for the determination of some secondary compounds of brazilian sugar cane spirits by gas chromatography. J. Agric. Food. Chem., v.49, n.8, p.3533-3539, 2001.

[19] NYKÄNEN, L.; NYKÄNEN, I. Rum Flavour. In: PIGGOTT, J. R. (Ed) Flavour of distilled beverages: origin and development. Chichester: Ellis Horwood Limited, 1983, Cap.3, p.49-63.

[20] NYKÄNEN, L.; NYKÄNEN, I. Distilled Beverages. In: MAARSE, H. (Ed) Volatile compounds in foods and beverages. New York: Marcel Dekker, 1991, Cap.15, p.547-580.

[21] RYCHLIK, M.; SCHIEBERLE, P.; GROSCH, W. 1998. Compilation of odor thresholds, odor qualities and retention indices of key food odorants. Technischen Univesität Munchen, Garching, Germany.

[22] SHAW, P. E. Fruits II. In: MAARSE, H. (Ed) Volatile compounds in foods and beverages. New York: Marcel Dekker, 1991, Cap.9, p.305-327.

[23] TAKEOKA, G. R.; FLATH, R. A.; MON, T. R.; TERANISHI, R.; GUENTERT, M. Volatile constituents of apricot (Prunus armeniaca). J. Agric. Food Chem., v.38, p.471-477, 1990.

[24] VAN GEMERT, L. M.; NETTENBREIJER, A. H. 1977. Compilation of odor threshold values in air and water. TNO-CIVO Food Analysis Institute, Zeist, The Netherlands.

[25] WHITFIELD, F. B.; MOTTRAM, D. S. Investigation on the reaction between 4-hydroxy-5-methyl-3(2H)-furanone and cysteine or hydrogen sulfide at $\mathrm{pH}$ 4.5. J. Agric. Food Chem, v.47, n.4, p.1626-1634, 1999.

[26] WILLIAMS, A. A. Flavour research and the cider industry. J. Inst. Brew., n.80, p.455-470, 1974. 